\title{
Modulating the phonological similarity effect: The contribution of interlist similarity and lexicality
}

\author{
PAUL JOHAN KARLSEN \\ University of Oslo, Oslo, Norway, \\ and New York University, New York \\ and \\ ARILD LIAN \\ Bredtvet Resource Center, Oslo, Norway
}

\begin{abstract}
The classical phonological similarity effect (PSE) was studied with words and nonwords in two immediate serial recall (ISR) tasks. The relative contributions of intralist and interlist interference were compared, and differential effects on item and order memory were observed. PSE occurred with words and was reversed with nonwords. In addition, PSE was modulated by interlist similarity, which enhanced recall of rhyme items and impaired recall of distinct items. Finally, interlist similarity reduced item recall of words, whereas it improved serial recall of nonwords. The latter finding rules out the hypothesis that the reverse PSE for nonwords is due to interlist interference. It is concluded that two opposing effects of phonological intralist similarity cause the interaction between PSE and lexicality in ISR. With words, the positive effect on item recall is usually masked by a much more disruptive effect on position accuracy. With nonwords, however, the positive effect often masks the negative one. These findings are discussed in relation to current models of verbal short-term memory.
\end{abstract}

Lists that contain similar-sounding items, such as mad can cat, are generally more difficult to retrieve in the order of presentation than lists that contain dissimilarsounding items, such as cow bar pen. This finding is known as the phonological similarity effect (PSE) in immediate serial recall (ISR). PSE was initially established with lists of consonant letters (Conrad, 1965; Conrad, Baddeley, \& Hull, 1966; Conrad, Freeman, \& Hull, 1965; Conrad \& Hull, 1964) but clearly extends to words (Baddeley, 1966; Brown \& Hulme, 1995; Henson, Norris, Page, \& Baddeley, 1996; Longoni, Richardson, \& Aiello, 1993; Nairne, 1990a; Schweickert, 1993; Schweickert, Guentert, \& Hersberger, 1990). The negative effect of phonological similarity is associated with confusions of serial order, or transpositions among the phonologically similar items in the list (Ellis, 1980; Healy, 1974; Murdock \& vom Saal, 1967; Wickelgren, 1965). Recall for items irrespective of order does not seem to be as negatively affected (Drewnowski, 1980; Fallon, Groves, \& Tehan, 1999; Henson, Hartley, Burgess, Hitch, \& Flude, 2003; Lian, Karlsen, \& Winsvold, 2001; Tehan, Hendry, $\&$ Kocinski, 2001). Now, 40 years after the original re-

This work was supported by a grant from the Norwegian Research Council to the authors. The authors gratefully acknowledge the assistance of Ingerid Borgerud, Thale Kristine Bostad, Cathrine Hallan, Camilla Nissen, Karl Johan Wikse, and Tone Helene Aarvik Wikse in testing the participants. We thank Elisabet Service and James S. Nairne for their helpful comments. Correspondence concerning this article should be addressed to P. J. Karlsen, Institute of Psychology, University of Oslo, Box 1094, N-0317 Oslo, Norway (e-mail: pjkarlse@psykologi. uio.no). port by Conrad and Hull, the explanation of PSE has become a touchstone of general models of verbal shortterm memory (Gathercole, 1997; Nairne \& Kelley, 1999; Page \& Norris, 1998).

Proponents of the phonological loop model take PSE to be a signature effect of the short-term phonological store (Baddeley, 1986; Baddeley \& Hitch, 1974). This store is dedicated to the temporary retention of speech sounds, and it is suggested that it evolved specifically to store unfamiliar speech patterns. Hence, it is believed to facilitate language learning and vocabulary acquisition (Baddeley, Gathercole, \& Papagno, 1998). Memory traces are assumed to decay rapidly and passively unless refreshed by active rehearsal. Random decay of phonemic segments increases the risk of confusions between phonologically similar recall candidates, thus causing PSE. The store is believed to account for much of subspan performance, when lists are shorter than four items (Cowan, 2001) and can be articulated within $2 \mathrm{sec}$. With longer lists and longer retention intervals, retrieval from long-term memory is believed to play an increasingly important role (Baddeley, 2003). Many models of verbal short-term memory (VSTM) do not pertain to accounts of lexical effects in ISR (e.g., Baddeley, 1986; Baddeley \& Hitch, 1974; Brown, Preece, \& Hulme, 2000; Burgess \& Hitch, 1992; Henson, 1998; Houghton, 1990; Nairne, 1990a; Neath, 1999; Neath \& Nairne, 1995; Page \& Norris, 1998; Schweickert et al., 1990), but a number of recent models have incorporated explanatory mechanisms that function independently of PSEs (Brown \& Hulme, 1995; Burgess \& Hitch, 1999; Gathercole \& Martin, 1996; 
Glasspool, 1995; Hulme, Newton, Cowan, Stuart, \& Brown, 1999; Lewandowsky \& Farrell, 2000). According to both sets of models, the PSE is the result of interference between acoustically or phonologically similar recall candidates. The phonological loop model and Nairne's (1990a) feature model seem to predict that the PSE should apply equally well to words and nonwords. For both types of material, there is a comparison between phonologically similar and phonologically distinct recall candidates. In addition, retention of nonwords is likely to rely more strongly on phonological features, because words probably activate more semantic and lexical representations than nonwords do. Thus, the feature model and the phonological loop model may be taken to predict that the PSE should be particularly strong for unfamiliar verbal material. However, the PSE is reversed for consonantvowel-consonant (CVC) trigrams that do not constitute words (Lian \& Karlsen, 2004; Lian, Karlsen, \& Eriksen, 2004; Lian et al., 2001). To account for this interaction, current models need to be modified, or some other, additional mechanism must be evoked. In the present article, two possible explanations of the reversal of the PSE for nonwords are tested.

Despite the importance ascribed to the PSE, the effect has been studied in extremely limited ways (Fallon et al., 1999; Graf, Braun, Jacobs, \& Hellbrück, 2002; Lian et al., 2004; Mueller, Seymour, Kieras, \& Meyer, 2003). Typically, phonological similarity has been defined in terms of a shared vowel sound or a rhyme component across items. Lian et al. (2004) noted that most research on the PSE in serial recall has focused on intralist or item similarity only, but manipulation of intralist similarity is likely to affect list similarity across trials. Consequently, the PSE is quite possibly a confound effect of both intralist and interlist similarity. When efforts have been made to study phonological item similarity in more detail, the PSE has been reversed under certain conditions, indicating a positive effect of phonological similarity on item recall. The PSE sometimes disappears when rhyme words are compared with phonologically distinct words (Fallon et al., 1999). A reversal has been reported when recall is scored for items correctly remembered regardless of order (Fallon et al., 1999; Tehan et al., 2001). According to these researchers, the phoneme(s) shared between phonologically similar items is likely to serve as a phonological category cue that improves item recall. This positive effect is often masked in the serial recall score by the negative effect on position accuracy. Finally, Nairne and Kelley (1999) manipulated intralist and interlist similarity independently by varying whether the same or different words occurred across trials. They reported a reversal of the PSE in a serial reconstruction task with a filled retention interval of $24 \mathrm{sec}$. The reversal occurred only when words were never repeated across lists (open set), and there was a classical PSE when words reoccurred (closed set). The positive effect on item recall becomes more apparent with time, as can be seen in delayed free recall (Lian et al., 2004), in which more phonologically similar items are recalled than phonologically distinct items. Item repetitions across trials may reduce such differences. Closed sets may thus remove the advantage for similar items in item recall.

In the present article, we investigate whether the reverse PSE with nonwords is due to differences in item recall or differences in interlist interference. Participants in serial recall experiments are required to recall items from the most recently presented list only. In order to bar interference from previous lists, they have to rely on the distinctiveness of the list taken as a whole. Nairne and colleagues (Nairne, 1990b; Nairne \& Kelley, 1999, 2004; Nairne \& Neumann, 1993) have argued that ordered recall performance is a function of both within- and acrosslist discriminability and that the two types of similarity may have differential effects on item and order information. Proactive interference (PI) due to list similarity is well known from the Brown-Peterson paradigm, which involves a filled retention interval of several seconds (Keppel \& Underwood, 1962). The negative effect affects memory span in ISR too (Lustig \& Hasher, 2002; Lustig, May, \& Hasher, 2001; Sanders \& Willemsen, 1978; Tehan \& Humphreys, 1995, 1998), but PI is not always observed (Dempster \& Cooney, 1982) and appears to be restricted to lists that consist of more than four items (Halford, Maybery, \& Bain, 1988). Only a few studies have noted the particular relationship between PI and phonological similarity in short-term memory tasks. Tehan and Humphreys (1995) found that PI corresponds in a principled fashion to the manipulation of phonemic information; Glassman (1972) established a clear relationship between PI and the acoustic list similarity of words, whereas Block (1971) observed that PI correlates with the acoustic similarity of trigrams across lists. M. Coltheart and Geffen (1970) reported a buildup of PI across four lists of three phonologically similar nonsense syllables and a release from PI on the fifth list, when a new phonological feature was introduced. A similar finding with words was reported by Henriksen, Fleming, and Pilichowski in 1974. Finally, in paired-associate retention, the acoustic similarity of left-hand members has been shown to increase PI (Bruce \& Murdock, 1968).

The inherent relationship between PI and phonological similarity has never been systematically investigated in ISR. Lian et al. (2004), however, argued that such a relationship could be responsible for the interaction between phonological similarity and lexicality. The change of shared phonemes from one list of phonologically similar items to another could be interpreted as a phonological category shift. A category shift would increase list distinctiveness and provide release from PI. Thus, both the positive effect of item similarity and the negative effect of PI are likely to enhance recall of phonologically similar items over distinct items. Both effects could be responsible for the reversal of the PSE for nonwords.

Words and nonwords consist of phonemic segments. The chunking of segments into larger units (e.g., Miller, 1956) improves recall, and the lexicality effect, involving 
higher recall for words than for nonwords, could be interpreted as a particular chunking phenomenon. Phonologically distinct nonwords are exceptionally difficult to chunk. A large number of phonological segments must be remembered per list, so the memory load for this type of material is extremely high. Thus, the reversal of the PSE for nonwords could be due to the large drop in item recall for phonologically distinct items.

On the other hand, lists of words are likely to activate more meanings than lists of nonwords do, so semantic distinctiveness might be greater for lists of words than for lists of nonwords. Lian et al. (2004) thus hypothesized that PI should be higher for nonwords than for words, particularly in the case of distinct nonwords, as reflected in a lower item recall score and a larger number of intrusions. The dominance of intralist interference over interlist interference may cause a classical PSE, whereas the dominance of interlist interference over intralist interference may cause a reversal of the PSE. Adults typically make more transposition errors than intrusions and omissions in serial recall of words. With nonwords, however, intrusions and omissions are more frequent than transpositions (e.g., Lian \& Karlsen, 2004). Such differences in error patterns may be due to differences in intralist interference and interlist interference across lexical conditions. Whereas intralist similarity is known to cause transpositions (Conrad, 1965; Drewnowski, 1980; Ellis, 1980; Healy, 1974; Murdock \& vom Saal, 1967; Wickelgren, 1965), interlist similarity is known to cause intrusions (Loess, 1968; Wickens, 1970; Wickens, Born, \& Allen, 1963; Wright, 1967).

One may want to distinguish between at least four levels of phonological similarity. As is shown in Table 1, there may be distinct lists of distinct items (Condition A), similar lists of distinct items (Condition B), distinct lists of similar items (Condition C), and similar lists of similar items (Condition D). The PSE will be confounded, for example, when distinct lists of similar items (Condition C) are compared with indistinct lists of distinct items (Condition B). To investigate the effects of "pure" intralist similarity, comparisons should be made between Conditions $\mathrm{A}$ and $\mathrm{C}$ or between Conditions $\mathrm{B}$ and D. To investigate the effects of "pure" interlist similarity, comparisons should be made between Conditions A and B or between Conditions C and D. Unfortunately, interlist and

Table 1

The Contribution of Interlist and Intralist Similarity to Interference Effects in Immediate Serial Recall

\begin{tabular}{llll}
\hline & \multicolumn{3}{c}{ Interlist Similarity } \\
\cline { 2 - 4 } Intralist Similarity & Low & High \\
\hline Low (distinct) & C: a i y a a $\varnothing$ e e e & D: a e o a e o \\
High (rhyme) & a a a \\
\hline
\end{tabular}

Note-The table presents an ideal experiment that allows for a complete disentanglement between the effects of interlist and intralist similarity. For the sake of simplicity, only the middle vowel of each study item is represented. Each sequence of three vowels signifies a study list in one serial recall trial. intralist similarity are intrinsically related and cannot be completely disentangled from one another. The pool of available letters is naturally restricted by the alphabet, and most experiments consist of many trials, so letters or speech sounds are likely to be repeated in random order across lists (e.g., "a e i" and "e a i"). Thus, Condition A would be very difficult to obtain. Most studies of the PSE probably compare some crossover between Conditions $\mathrm{A}$ and $\mathrm{B}$ with some crossover between $\mathrm{C}$ and $\mathrm{D}$, but we suspect that the latter crossover often converges toward Condition C. List similarity, then, confounds the effects of item similarity. Consequently, the PSE could be the combined effect of both types of similarity.

There is a logical distinction between the inherent relationship between intralist and interlist similarity, on the one hand, and the effects of that relationship, on the other. The argument of the present article is that phonological item similarity becomes inversely related to phonological list similarity. Lists of rhyme items will be highly distinct when compared with adjacent lists, whereas lists of phonologically distinct items will appear much more similar to each other. Consequently, PI should be more of a problem for lists of distinct items than for lists of rhyme items. Fallon et al. (1999) noted that item similarity is likely to serve as an effective retrieval cue that could boost item recall. The same could be true of list similarity. PI could mask a positive effect of list similarity on the generation of recall candidates. Thus, the effect of list similarity may differ as a function of intralist similarity.

The present study consisted of two experiments. In Experiment 1 , two levels of phonological item similarity were presented blockwise. The middle vowels were changed from one list to the other or kept constant across lists within a block. This manipulation made for the variation in interlist similarity-low versus high. In Experiment 2, four levels of phonological item similarity were compared. Vowels were always switched across lists, and interlist similarity was manipulated by presenting the phonological categories either blockwise or in mixed order. Nairne and Kelley (1999), for example, used mixed order presentation, whereas Fallon et al. (1999) used blocked order presentation. The two designs have never been systematically compared in studies of the PSE, despite their well-documented impact on word frequency effects in free recall (see Gillund \& Shiffrin, 1984; Karlsen $\&$ Snodgrass, 2004). The high interlist similarity condition in Experiment 1 involved the greatest interlist similarity in the present study (Level 1). This condition is similar to Categories B and D in Table 1. The low interlist similarity condition in Experiment 1 and the blockwise condition in Experiment 2 represented a midlevel (Level 2). These conditions are similar to Category $\mathrm{C}$ and some overlap between A and B. We suspect that most studies of the PSE compare these conditions. The lowest level of interlist similarity was provided by the mixed order condition in Experiment 2 (Level 3). This level also corresponds to Categories $\mathrm{C}$ and $\mathrm{A} / \mathrm{B}$, except that lists from the contrasting categories were mixed together. 
If the PSE is largest at Level 3, smaller at Level 2, and smallest at Level 1, the PSE is inversely related to interlist similarity. Furthermore, if the interaction between phonological similarity and lexicality is caused by differences in interlist interference, there should be a threeway interaction between intralist similarity, interlist similarity, and lexicality on the serial recall score. If there is no negative effect of interlist similarity on recall for nonwords, differences in item memory load across phonological conditions are probably the main reason for the reversal of the PSE. If the interaction between phonological item similarity and lexicality in fact extends to phonological list similarity, Fallon et al.'s (1999) itemcuing hypothesis has received further support. Finally, by employing visual presentation, the present study tests whether the previously established reversal of the PSE for auditorily presented nonwords extends to the visual domain.

If the PSE is affected by interlist similarity, as well as by lexicality, it becomes less clear that the PSE is a pure signature effect of a short-term phonological store. An interaction between interlist similarity and lexicality, analogous to the one between intralist similarity and lexicality, further complicates this picture. Some temporary traces are probably refreshed across lists, because each new trial may involve some rehearsal of previously studied material. But robust effects across experimental trials are probably due to long-term memory retention beyond the phonological store. Existing models of VSTM cannot explain such findings unless they are modified, or some other, additional mechanism is evoked to account for the interactions.

\section{EXPERIMENT 1}

This experiment tested whether interlist similarity modulates the PSE in ISR of visually presented words and nonwords. The experiment also tested whether a larger disruptive effect of interlist similarity is responsible for the reverse PSE with nonwords. Two intralist conditions, rhyme items versus phonologically distinct items, were presented in blockwise order. Vowels were either changed across lists or kept constant within the block. When the vowels were changed, the lists became more distinct, and when they were kept constant, the lists became more similar. Consonant information, on the other hand, always varied across lists. The high interlist similarity condition corresponds to Categories B and D in Table 1. Thus, a total of four combinations of intralist and interlist similarities were compared for words, highassociative nonwords, and low-associative nonwords. Lists consisted of either six words or five nonwords, and there were few item repetitions across lists. Because word span is higher than nonword span (see, e.g., Brown \& Hulme, 1995; Crowder, 1976; Gathercole, Frankish, Pickering, \& Peaker, 1999; Gathercole, Pickering, Hall, \& Peaker, 2001; Hulme et al., 1999; Multhaup, Balota, \& Cowan, 1996), different list lengths were imposed, in order to provide less difference in short-term memory demands across lexical conditions.

\section{Method}

Participants. Forty-eight participants, 28 females and 20 males, were recruited from the student population at the University of Oslo. All of them were native speakers of Norwegian, with normal or corrected vision, and within the age range of 21-43 years.

Design. For words, the experiment was conducted according to a $2 \times 2$ within-group design. The independent variables were intralist phonological similarity (distinct vs. rhyme items) and interlist phonological similarity (low vs. high). For nonwords, the experiment was conducted according to a $2 \times 2 \times 2$ within-group design, the third variable being associative value (low vs. high).

Materials and Pretest. There was no absolute distinction between words and nonwords in the present study. A quarter of the trigrams occur as word forms in the Oslo Corpus of Tagged Norwegian Texts (2000), most of them with extremely low frequency. Nonword lists consisted of either high- or low-associative CVC trigrams, as defined by a preliminary reaction time (RT) assessment. The pretest was similar to that used in previous studies (Lian et al., 2004; Lian et al., 2001), but this time the nonwords were presented visually, not auditorily. High-associative nonwords were assumed to be more wordlike and better connected to long-term memory representations than the low-associative nonwords were. In addition, the associative value of the CVC nonwords was clearly related to the phonotactic frequencies of the biphones $\mathrm{CV}$ and $\mathrm{VC}$, since the mean biphone frequency was higher for the high-associative than for the low-associative trigrams in both Experiment $1[t(158)=$ $4.08, p<.001]$ and Experiment $2[t(158)=3.88, p<.001]$ of the present study.

For the pretest, $196 \mathrm{CVC}$ trigrams were created by exhaustively combining the seven letters $d, g, k, l, r, s$, or $t$ as the initial consonant, the seven letters $a, e, i, o, u, c$, or $a$ as the middle vowel, and the four letters $b, v, f$, or $p$ as the end consonant-for example, $d a b$. The trigrams are all easily pronounceable in Norwegian. Twenty-six students, 16 females and 10 males, participated in the pretest. They were all native speakers of Norwegian, had normal or corrected vision, and were within the age range of 23-27 years. The trigrams were presented one by one on the center of a computer screen, and the participants were instructed to utter as quickly as possible the first verbal association that came to mind for each trigram, while simultaneously pressing the space bar of the computer keyboard. Test items remained on the screen until a response was recorded.

After the pretest, the 196 trigrams were split into two groups by the median RT. Items that, across participants, gave rise to short RTs (below the median) were considered to have high associative value, and items that gave rise to long RTs (above the median) were considered to have low associative value (Lian et al., 2001). Whereas associative value did not differ across phonological conditions, the logarithmically transformed RTs were significantly shorter for the high- than for the low-associative trigrams in both Experiments 1 and 2 of the present study $[t(158)=14.71, p<.001$, and $t(157)=$ $15.12, p<.001$, respectively].

A total of 48 lists were presented to each participant (see Appendix A). There were 16 word lists with six items each, 16 highassociative trigram lists with five items each, and 16 low-associative trigram lists with five items each. The words mimicked the phonological structure of the trigrams and were of medium frequency in the natural language, according to the Oslo Corpus of Tagged Norwegian Texts (2000). The words often included consonant clusters, whereas the nonwords never did. Intralist similarity was manipulated by creating lists of phonologically distinct items (low intralist similarity) and lists of items that shared the final vowel and consonant(s) (rhyme lists; high intralist similarity). Interlist similarity was manipulated by creating blocks of lists that shared the middle vowel (high interlist similarity) and blocks of lists with differing vowels 
(low interlist similarity). There were four lists within each condition. Hence, a total of 96 words, 80 high-associative trigrams, and 80 low-associative trigrams were used in the experiment. In order to create enough lists with enough items from a limited material, there were eight item repetitions - that is, $5 \%$ of items were repeated across lists. There were five crossovers from the high-associative pool to lists of low-associative items and three crossovers from the low-associative pool to lists of high-associative items. In addition, there were some crossovers that were not repetitions. There were four such nonrepetition crossovers from the high- to the low-associative pool and five nonrepetition crossovers from the low- to the highassociative pool. However, all the crossovers had RTs very close to the median in the assessment of associative value.

Procedure. The participants signed an informed consent and were told in advance to expect a serial recall test after each list presentation. They were also told whether to expect words or trigrams and whether to expect six or five items. They were given two practice trials and were instructed to study each list item carefully without reading it out loud. The sequence of lists within a phonological category was randomized. Experimental conditions were presented blockwise, the sequence of which was balanced according to a Latin square design. Each list item was presented for $1.0 \mathrm{sec}$ on the center of the computer screen, followed by a 0.5 -sec interstimulus interval. When the screen remained blank, the participants were instructed to write down immediately as many items as possible in the order of presentation, by filling out a response form containing six boxes in the case of the words and five boxes in the case of the trigrams. The boxes were marked with the numbers $1-6$ and $1-5$, respectively. The participants were told to leave a box blank if they could not recall the corresponding item presented in that particular position, but qualified guessing was encouraged. No time limit was imposed during the test phase, and the participants generally finished writing down items within $10-15 \mathrm{sec}$. Afterward, they pressed a key to get the list number on the screen, and they wrote that number on top of the response form before turning it upside down. It usually took the participants $20-30 \mathrm{~min}$ to complete the 48 trials. The experimenter then scored, for each list position (1-5 or 1-6), whether the item was recalled in correct position or whether there was an omission, transposition, repetition, or intrusion in that list position. A response was scored as correct only when the trigram or the word was correctly spelled.

\section{Results and Discussion}

Average memory performance is presented in Tables 2 (words) and 3 (nonwords). Analyses of variance (ANOVAs)
Table 2

Item Recall, Serial Recall, and Position Accuracy Scores for Lists of Six Words in Experiment 1

\begin{tabular}{|c|c|c|c|c|c|c|}
\hline \multirow[b]{3}{*}{ Intralist Similarity } & \multicolumn{6}{|c|}{ Interlist Similarity } \\
\hline & \multicolumn{3}{|c|}{ Low } & \multicolumn{3}{|c|}{ High } \\
\hline & Item & Serial & Accuracy & Item & Serial & Accuracy \\
\hline \multicolumn{7}{|l|}{ Words } \\
\hline Distinct (low) & .78 & .72 & .93 & .69 & .66 & .95 \\
\hline Rhyme (high) & .77 & .64 & .81 & .78 & .65 & .83 \\
\hline$M$ & .78 & .68 & .87 & .74 & .66 & .89 \\
\hline
\end{tabular}

Note-Distinct items, low intralist similarity; rhyme items, high intralist similarity; item, mean proportion of items recalled regardless of position; serial, mean proportion of items recalled in correct position; accuracy, mean position accuracy as defined by the ratio between serial and item recall scores.

for repeated measures were performed on serial recall, item recall, and position accuracy scores for words and nonwords separately, and always on the average proportions of correct items. Separate ANOVAs for repeated measures were also conducted on the different error types. The measures will be described in individual sections. Bonferroni adjustments were conducted on all post hoc $t$ test comparisons between phonological categories.

Item recall. For words recalled regardless of position, there was a main effect of intralist similarity $[F(1,47)=$ $6.57, p<.05]$, which means that more rhyme words were recalled than phonologically distinct words-in other words, a positive effect of phonological similarity on item recall. There was also a main effect of interlist similarity $[F(1,47)=8.06, p<.01]$, which means that item recall was higher for distinct lists (with differing vowels) than for similar lists (with shared vowels). This effect was due to a two-way interaction between intralist similarity and interlist similarity $[F(1,47)=9.89, p<$ $.01]$, which means that list similarity modulated the PSE. List similarity selectively reduced item recall for distinct items $[t(47)=3.85, p<.001]$ and did not affect item recall for rhyme items $(t<1)$. The latter finding suggests that interlist similarity caused PI for distinct items only.

Table 3

Item Recall, Serial Recall, and Position Accuracy Scores for Lists of Five High- or Low-Associative Nonwords in Experiment 1

\begin{tabular}{|c|c|c|c|c|c|c|}
\hline \multirow[b]{3}{*}{ Intralist Similarity } & \multicolumn{6}{|c|}{ Interlist Similarity } \\
\hline & \multicolumn{3}{|c|}{ Low } & \multicolumn{3}{|c|}{ High } \\
\hline & Item & Serial & Accuracy & Item & Serial & Accuracy \\
\hline \multicolumn{7}{|c|}{ High-associative nonwords } \\
\hline Distinct (low) & .53 & .52 & .98 & .54 & .53 & .98 \\
\hline Rhyme (high) & .82 & .69 & .87 & .86 & .78 & .91 \\
\hline$M$ & .68 & .62 & .93 & .70 & .66 & .95 \\
\hline \multicolumn{7}{|c|}{ Low-associative nonwords } \\
\hline Distinct (low) & .51 & .50 & .96 & .46 & .45 & .97 \\
\hline Rhyme (high) & .79 & .63 & .79 & .80 & .70 & .85 \\
\hline$M$ & .65 & .57 & .88 & .63 & .58 & .91 \\
\hline
\end{tabular}

Note-Distinct items, low intralist similarity; rhyme items, high intralist similarity; item, mean proportion of items recalled regardless of position; serial, mean proportion of items recalled in correct position; accuracy, mean position accuracy as defined by the ratio between serial and item recall scores. 
For nonwords recalled regardless of position, there was a main effect of association value $[F(1,47)=9.47$, $p<.01]$, which means that high-associative nonwords were recalled better than low-associative nonwords, consistent with previous findings (Lian et al., 2004). There was another main effect of intralist similarity $[F(1,47)=$ $315.75, p<.001]$, which again reflects the fact that item recall was higher for rhyming items than for distinct items - in other words, a positive effect of phonological similarity on item recall. In contrast to words, there was no main effect of interlist similarity $(F<1)$, but the twoway interaction between intralist similarity and interlist similarity approached significance $[F(1,47)=3.53, p=$ $.07]$, which suggests that interlist similarity caused a greater reversal of the PSE. Interlist similarity did improve item recall for rhyme items $[t(47)=2.18, p<.05]$ but had little effect on item recall for distinct nonwords $(t<1)$. The latter findings seem to rule out the hypothesis that the reverse PSE for nonwords is due to an increase in interlist interference.

Serial recall. For words recalled in correct position, there was a main effect of intralist similarity $[F(1,47)=$ $6.53, p<.05]$, which means that distinct words were recalled better than rhyme words - that is, a classical PSE. There was no main effect of interlist similarity $[F(1,47)<$ $2.17, p>.14]$. However, the two-way interaction between intralist similarity and interlist similarity was significant $[F(1,47)=4.63, p<.05]$. Thus, interlist similarity modulates the PSE; the effect is not present when interlist similarity is high $[t(47)=3.56, p<.01 ; t<1]$.

For nonwords recalled in correct position, there was a main effect of associative value $[F(1,47)=13.43, p<$ $.01]$, which means that high-associative nonwords were recalled better than low-associative nonwords, consistent with previous findings (Lian et al., 2004). There was also a main effect of intralist similarity $[F(1,47)=91.02, p<$ $.001]$, which means that PSE was reversed for nonwords; in other words, more rhyme nonwords than distinct nonwords were recalled in correct position. There was a main effect of interlist similarity $[F(1,47)=7.42, p<$ $.01]$, which means that interlist similarity improved serial recall of nonwords. This finding rules out the hypothesis that the reverse PSE for nonwords is due to an increase in interlist interference. The two-way interaction between intralist similarity and interlist similarity was clearly significant $[F(1,47)=10.39, p<.01]$, which means that interlist similarity modulates the PSE, and that the reversal increases with higher interlist similarity [low interlist similarity, $t(47)=5.93, p<.001$; high interlist similarity, $t(47)=10.22, p<.001]$.

Position accuracy. For the proportion of words recalled in correct position (i.e., the ratio between serial recall and item recall), there was a main effect of intralist similarity $[F(1,47)=36.49, p<.001]$ - that is, the PSE occurred, consistent with previous findings. There was no main effect of interlist similarity and no two-way interaction between interlist and intralist similarity $\left(F_{\mathrm{S}}<1\right)$.

For the proportion of nonwords recalled in correct position, there was a main effect of associative value $[F(1,47)=$ $8.62, p<.01]$, which means that high-associative nonwords were more accurately recalled than low-associative nonwords. More important, there was another main effect of intralist similarity $[F(1,47)=74.00, p<.001]$, which means that position accuracy was higher for phonologically distinct items than for rhyming items, regardless of lexicality. In contrast to words, there was also a main effect of interlist similarity $[F(1,47)=4.66, p<.05]$, which means that interlist similarity improves position accuracy for nonwords. The two-way interaction between intralist similarity and interlist similarity approached significance $[F(1,47)=3.47, p=.07]$, which suggests that position accuracy improves for rhyme nonwords when interlist similarity is high $[t(47)=2.15, p<.05]$.

Error patterns. The four error types were intrusions (extralist items), repetitions (incorrect repetitions of an otherwise correct list item), omissions (no response given for a particular position in a list), and transpositions (confusion of order for an otherwise correct list item). Mean proportions of errors per list position were calculated. Error patterns for words and nonwords are presented in Tables 4 and 5, respectively. The protocol of error scores is exhaustive, in the sense that the sum of intrusions, repetitions, omissions, and transpositions equals 1 minus the serial recall score. For words, the error types can be ranked in the following order, according to frequency: omissions $>$ transpositions $>$ intrusions $>$ repetitions. Repetitions hardly ever occurred in this experiment, since the required written responses were efficient reminders of previous responses. Separate ANOVAs for repeated measures were performed on the average probability per presented item for each of the error types. Transpositions and repetitions occurred more frequently with rhyme words than with distinct words $[F(1,47)=$ $65.24, p<.001$, and $F(1,47)=7.67, p<.01$, respec-

Table 4

Proportion of Errors According to Error Type for Words in Experiment 1

\begin{tabular}{|c|c|c|c|c|c|c|c|c|}
\hline \multirow[b]{2}{*}{ Words } & \multicolumn{2}{|c|}{ Transpositions } & \multicolumn{2}{|c|}{ Intrusions } & \multicolumn{2}{|c|}{ Repetitions } & \multicolumn{2}{|c|}{ Omissions } \\
\hline & $\mathrm{L}$ & $\mathrm{H}$ & $\mathrm{L}$ & $\mathrm{H}$ & $\mathrm{L}$ & $\mathrm{H}$ & $\mathrm{L}$ & $\mathrm{H}$ \\
\hline Distinct (low) & .05 & .03 & .06 & .13 & .01 & .01 & .16 & .17 \\
\hline Rhyme (high) & .14 & .13 & .06 & .07 & .01 & .02 & .15 & .13 \\
\hline$M$ & .10 & .08 & .06 & .10 & .01 & .02 & .15 & .15 \\
\hline
\end{tabular}

Note-L, low interlist similarity; H, high interlist similarity; low, low intralist similarity; high, high intralist similarity. 
Table 5

Proportion of Errors According to Error Type for Nonwords in Experiment 1

\begin{tabular}{|c|c|c|c|c|c|c|c|c|}
\hline \multirow[b]{2}{*}{ Nonwords } & \multicolumn{2}{|c|}{ Transpositions } & \multicolumn{2}{|c|}{ Intrusions } & \multicolumn{2}{|c|}{ Repetitions } & \multicolumn{2}{|c|}{ Omissions } \\
\hline & $\mathrm{L}$ & $\mathrm{H}$ & $\mathrm{L}$ & $\mathrm{H}$ & $\mathrm{L}$ & $\mathrm{H}$ & $\mathrm{L}$ & $\mathrm{H}$ \\
\hline \multicolumn{9}{|l|}{ High associative } \\
\hline Distinct (low) & .01 & .01 & .36 & .37 & .00 & .00 & .11 & .09 \\
\hline Rhyme (high) & .12 & .08 & .10 & .08 & .00 & .00 & .08 & .05 \\
\hline$M$ & .06 & .05 & .23 & .23 & .00 & .00 & .10 & .07 \\
\hline \multicolumn{9}{|l|}{ Low associative } \\
\hline Distinct (low) & .01 & .01 & .35 & .40 & .00 & .00 & .14 & .14 \\
\hline Rhyme (high) & .15 & .10 & .10 & .11 & .01 & .01 & .10 & .08 \\
\hline$M$ & .08 & .06 & .23 & .26 & .01 & .01 & .12 & .11 \\
\hline
\end{tabular}

Note-L, low interlist similarity; $\mathrm{H}$, high interlist similarity; low, low intralist similarity; high, high intralist similarity.

tively], whereas intrusions were more frequent with distinct words $[F(1,47)=11.44, p<.01]$. In addition, interlist similarity caused an increase in intrusions $[F(1,47)=$ $21.29, p<.001]$, especially with distinct words, as reflected by the two-way interaction between intralist and interlist similarity $[F(1,47)=12.99, p<.01]$. This observation indicates that interlist similarity causes PI for distinct words in particular.

For nonwords, the error types can be ranked in the following order, according to frequency: intrusions $>$ omissions $>$ transpositions $>$ repetitions. Thus, intrusions occurred more frequently with nonwords, whereas transpositions occurred more frequently with words, consistent with previous findings. Intrusions and omissions occurred more often with distinct nonwords $[F(1,47)=$ $277.19, p<.001$, and $F(1,47)=17.83, p<.001$, respectively], and transpositions and repetitions occurred more often with rhyme nonwords $[F(1,47)=113.22$, $p<.001$, and $F(1,47)=9.40, p<.01$, respectively]. In addition, interlist similarity reduced the number of omissions $[F(1,47)=10.96, p<.01]$ and the number of transpositions $[F(1,47)=12.37, p<.01]$. However, the latter effect was due to a two-way interaction between intralist and interlist similarity $[F(1,47)=12.57, p<$ $.01]$, which means that transpositions were reduced with rhyme nonwords. Finally, list similarity seemed to cause a greater proportional increase in intrusions for distinct words than for distinct nonwords. This observation rules out the hypothesis that the reverse PSE for nonwords is due to an increase in interlist interference.

Summary. The results of Experiment 1 suggest that interlist similarity modulates the PSE. The PSE disappeared for words in the high interlist similarity condition, and the reversal of the PSE for nonwords increased. Thus, the PSE appears to be inversely related to interlist similarity in ISR. The interaction between intralist similarity and lexicality was not associated with a larger disruptive effect of interlist similarity on recall of nonwords. This finding rules out the possibility that the interaction between intralist similarity and lexicality is due to differences in interlist similarity. Instead, the positive effect of interlist similarity on serial recall of nonwords echoes the previously established interaction be- tween intralist similarity and lexicality. Thus, the reverse PSE seems to be due solely to differences in item recall across phonological conditions. Experiment 2 provided another test of this possibility.

\section{EXPERIMENT 2}

In this experiment, we further investigated how the PSE is modulated by interlist similarity. In addition, the experiment presented another test of whether the reverse PSE with nonwords is due to an increased disruptive effect of interlist similarity. In the present experiment, interlist similarity was manipulated by presenting phonological categories either blockwise or in mixed order. Vowels were always switched across lists. Thus, the blockwise condition was similar to the low interlist similarity condition in Experiment 1. With respect to Table 1, the blockwise condition thus corresponds to Category $\mathrm{C}$ in the case of similar items and to some mixture between Categories A and B in the case of distinct items. Blockwise presentation can be assumed to cause greater PI for distinct items than for phonologically similar items, because adjacent lists of distinct items appear to be more similar than adjacent lists of phonologically similar items. Four levels of intralist similarity were investigated. Phonologically distinct items were compared with similar items with no rhyme component, rhyme items, and consonant frame items. The four phonological categories were compared for words, high-associative nonwords, and lowassociative nonwords. There were either six words or five nonwords in the list. Memory span is higher for words than for nonwords (see the introduction to Experiment 1), so list length for nonwords was reduced to provide less difference in short-term memory demands across lexical conditions. There were few item repetitions across lists.

\section{Method}

Participants. Seventy-two participants, 43 females and 29 males, were recruited from the student population at the University of Oslo. They were all native speakers of Norwegian, with normal or corrected vision, and within the age range of $20-34$ years.

Design. For words, the experiment was conducted according to a $2 \times 4$ mixed design, with list order as a between-groups variable of two levels and intralist similarity as a within-subjects variable of 
four levels. For nonwords, the experiment was conducted according to a $2 \times 2 \times 4$ mixed design. The extra within-subjects variable was associative value (low vs. high). Lists were presented either in mixed order, irrespective of phonological categories, or blockwise according to the four phonological categories.

Materials. A total of 48 lists were presented to each participant (see Appendix B). There were 16 word lists with six items each, 16 high-associative trigram lists with five items each, and 16 lowassociative trigram lists with five items each. Trigrams were selected from the same pool of items as that described in the Method section in Experiment 1. Words mimicked the phonological structure of trigrams and were of medium frequency according to the Oslo Corpus of Tagged Norwegian Texts (2000). The words often included consonant clusters, whereas the nonwords never did. The four phonological categories of study lists were (1) lists of rhyming items that formed consonant contrasts that varied only in the initial consonant, such as tiv kiv piv riv liv (referred to as rhyme items); (2) lists of rhyming items that formed vowel contrasts, which vary only in their middle vowel, such as kab keb kob kåb kub (referred to as consonant frame items); (3) lists of items that shared the midvowel but differed with respect to initial and final consonants, such as fab laf sav rap kaf (referred to as similar nonrhyme items); and (4) lists of phonologically distinct items, such as vur nev kon sid båp (referred to as distinct items). Four lists were created for each withingroup condition. Hence, a total of 96 words, 80 high-associative trigrams, and 80 low-associative trigrams were used in the experiment. In order to create enough lists with enough items from a limited material, there were seven nonword repetitions across lists. There were five crossovers from the high-associative pool to lists of low-associative items and two crossovers from the low-associative pool to lists of high-associative items. All the crossovers had RTs very close to the median in the assessment of associative value. In addition, there were five repetitions across phonological categories of high-associative trigrams, so a total of $7.5 \%$ items were repeated once in this experiment. Finally, there was one nonrepetition crossover from high- to low-associative nonwords and one nonrepetition crossover from low- to high-associative nonwords.

Procedure. The participants were randomly assigned to one of two groups. One group studied lists in random order, irrespective of phonological category. The other group studied lists blocked according to phonological category. The sequence of lists within a phonological category was randomized. The lists were blocked according to their associative value and lexical status, and their order of presentation was balanced according to a Latin square design. The participants signed an informed consent and were told in advance to expect a recall test after each list presentation. They were also told whether to expect words or trigrams and whether to expect six or five items. The participants were given two practice trials and were asked to study all the items carefully without reading them out loud. Each list item was presented for $1.0 \mathrm{sec}$ on the middle of the computer screen, followed by a 0.5 -sec interstimulus interval. When the screen remained blank, the participants were instructed to write down immediately as many items as possible in the order of presentation, by filling out a response form containing six boxes in the case of words and five boxes in the case of trigrams. The boxes were marked with the numbers 1-6 and 1-5, respectively, and the participants were told to leave a box blank if they could not recall the corresponding item presented in that particular position, but qualified guessing was encouraged. No time limit was imposed during the test phase, and the participants generally finished writing down items within 10-15 sec. Afterward, they pressed a key to get the list number on the screen, and they wrote that number on top of the response form before turning it upside down. The 48 trials took the participants 20-30 min to complete. The experimenter scored for each list position whether the presented item was recalled or whether there was an omission, transposition, repetition, or intrusion in that position. A response was scored as correct only when the trigram or word was correctly spelled.

\section{Results and Discussion}

Average memory performance is presented in Tables 6 (words) and 7 (nonwords). ANOVAs for repeated measures, with one between-groups variable, were performed on serial recall, item recall, position accuracy scores for words and nonwords separately, and always on the average proportions of correct items. Separate ANOVAs for repeated measures were also conducted on the different error types. The scores will be described in individual sections. Bonferroni adjustments were performed on all post hoc $t$ tests of differences between phonological categories. There was no main effect of the between-groups variable list order in any of these comparisons $[F(1,70)<1]$, so there was no overall difference in interlist interference between the mixed and the blocked versions of the experiment.

Item recall. For words recalled regardless of position, there was a main effect of intralist similarity $[F(3,68)=$ $20.43, p<.001]$. The four phonological categories can be ranked in the following order, according to mean item recall scores: consonant frame $>$ distinct and rhyme $>$ similar nonrhyme. Item recall was particularly low for similar nonrhyme words, which were worse than consonant frame words $[t(71)=7.36, p<.001]$, rhyme words $[t(71)=6.43, p<.001]$, and distinct words $[t(71)=$ $6.29, p<.001]$. Item recall did not differ between distinct and rhyme words $(t<1)$, and it was particularly high for consonant frame words $[t(71)=2.11, p<.05$, and $t(71)=2.28, p<.05]$. There was no interaction between intralist similarity and list order $(F<1)$.

For nonwords recalled regardless of position, there was a main effect of associative value $[F(1,70)=16.13$, $p<.001]$, which means that performance was higher with high-associative nonwords than with low-associative nonwords. Again, there was a main effect of intralist similarity $[F(3,68)=212.64, p<.001]$, which means that the four phonological categories can be ranked in the following order, according to mean item recall scores: consonant frame and rhyme $>$ distinct $>$ similar nonrhyme. Both consonant frame and rhyme nonwords were better recalled than distinct nonwords $[t(71)=17.47$,

Table 6

Item Recall, Serial Recall, and Position Accuracy Scores for Mixed and Blockwise Presentation of Words According to Intralist Conditions in Experiment 2

\begin{tabular}{|c|c|c|c|c|c|c|}
\hline \multirow[b]{3}{*}{ Intralist Similarity } & \multicolumn{6}{|c|}{ Interlist Similarity } \\
\hline & \multicolumn{3}{|c|}{ Mixed } & \multicolumn{3}{|c|}{ Blocked } \\
\hline & Item & Serial & Accuracy & Item & Serial & Accuracy \\
\hline \multicolumn{7}{|l|}{ Words } \\
\hline Distinct & .69 & .63 & .91 & .70 & .62 & .89 \\
\hline Similar nonrhyme & .63 & .56 & .89 & .59 & .51 & .87 \\
\hline Rhyme & .71 & .51 & .71 & .70 & .55 & .78 \\
\hline Consonant frame & .73 & .59 & .81 & .73 & .57 & .78 \\
\hline$M$ & .69 & .57 & .83 & .68 & .56 & .83 \\
\hline
\end{tabular}

Note-Item, mean proportion of items recalled regardless of position; serial, mean proportion of items recalled in correct position; accuracy, mean position accuracy as defined by the ratio between serial and item recall scores. 
Table 7

Item Recall, Serial Recall, and Position Accuracy Scores for Mixed and Blockwise Presentation of Nonwords According to Intralist Conditions in Experiment 2

\begin{tabular}{|c|c|c|c|c|c|c|}
\hline \multirow[b]{3}{*}{ Intralist Similarity } & \multicolumn{6}{|c|}{ Interlist Similarity } \\
\hline & \multicolumn{3}{|c|}{ Mixed } & \multicolumn{3}{|c|}{ Blocked } \\
\hline & Item & Serial & Accuracy & Item & Serial & Accuracy \\
\hline \multicolumn{7}{|c|}{ High-associative nonwords } \\
\hline Distinct & .48 & .44 & .91 & .46 & .42 & .91 \\
\hline Similar nonrhyme & .48 & .43 & .88 & .40 & .33 & .82 \\
\hline Rhyme & .80 & .64 & .79 & .82 & .67 & .80 \\
\hline Consonant frame & .80 & .67 & .84 & .80 & .62 & .76 \\
\hline$M$ & .64 & .55 & .86 & .62 & .51 & .82 \\
\hline \multicolumn{7}{|c|}{ Low-associative nonwords } \\
\hline Distinct & .47 & .45 & .95 & .45 & .43 & .95 \\
\hline Similar nonrhyme & .42 & .34 & .82 & .37 & .31 & .85 \\
\hline Rhyme & .72 & .54 & .74 & .76 & .60 & .77 \\
\hline Consonant frame & .77 & .65 & .84 & .78 & .62 & .79 \\
\hline$M$ & .60 & .50 & .83 & .59 & .49 & .83 \\
\hline
\end{tabular}

Note-Item, mean proportion of items recalled regardless of position; serial, mean proportion of items recalled in correct position; accuracy, mean position accuracy as defined by the ratio between serial and item recall scores.

$p<.001$, and $t(71)=16.57, p<.001$, respectively] whereas item recall was higher for distinct than for similar nonrhyme nonwords $[t(71)=3.52, p<.01]$. In addition, there was a two-way interaction between intralist similarity and list order $[F(3,68)=3.32, p<.05]$, which means that the blocked condition impaired item recall for similar nonrhyme nonwords $[t(71)=2.43, p<.05]$. There was no difference for the other categories $(t \mathrm{~s}<$ $1.04, p>.30)$.

Serial recall. For words recalled in correct position, there was a main effect of intralist similarity $[F(3,68)=$ $13.43, p<.001]$, which reflects the fact that phonologically distinct items were recalled better than all three phonologically similar categories - that is, a classical PSE. Serial recall of distinct words was better than serial recall of consonant frame words $[t(71)=2.90, p<$ $.05]$, rhyme words $[t(71)=5.22, p<.001]$, and similar nonrhyme words $[t(71)=5.68, p<.001]$. The two-way interaction between intralist similarity and list order approached significance $[F(3,68)=2.33, p=.09]$, which means that the PSE tends to differ somewhat in the blocked and the mixed conditions. The blocked condition improves recall for rhyme items, while impairing recall for the other phonological categories.

For nonwords recalled in correct position, there was a main effect of associative value $[F(1,70)=10.97, p<$ $.01]$, which means that serial recall was higher for highassociative nonwords than for low-associative nonwords. There was another main effect of intralist similarity $[F(3,68)=95.75, p<.001]$, which this time reflects the fact that the PSE was reversed for consonant frame and rhyme nonwords $[t(71)=10.86, p<.001$, and $t(71)=$ $8.86, p<.001$, respectively]. There was no difference between rhyme and consonant frame nonwords $[t(71)<$ $1.39, p>.17]$. For similar nonrhyme items, there was a classical PSE $[t(71)=5.68, p<.001]$. The two-way interaction between intralist similarity and list order ap- proached significance $[F(3,68)=2.20, p=.10]$, suggesting that the blocked condition improves serial recall for rhyme items, while impairing serial recall for the other phonological categories, particularly the similar nonrhyme nonwords. When high- and low-associative nonwords were collapsed together and compared with words in a further ANOVA for repeated measures with one between-groups variable, the two-way interaction between intralist similarity and list order turned significant $[F(3,68)=4.03, p<.05]$, which means that list order affects the PSE. Recall for rhyme items was slightly improved in the blocked condition, whereas recall for the other categories, particularly similar nonrhyme items, was reduced. However, interference in the blocked condition was no greater with nonwords than with words. This finding rules out the hypothesis that the reverse PSE for nonwords is due to an increase in interlist interference.

Position accuracy. For the proportion of words recalled in correct position - that is, the ratio between serial recall and item recall - there was a main effect of intralist similarity $[F(3,68)=31.44, p<.001]$, which means that a PSE was obtained. Position accuracy was higher for phonologically distinct words than for consonant frame words $[t(71)=6.81, p<.001]$ and rhyme words $[t(71)=7.48, p<.001]$, but the difference in position accuracy between distinct and similar nonrhyme words was nonsignificant $[t(71)=1.25, p>.21]$. The two-way interaction between intralist similarity and list order was also nonsignificant $[F(3,68)=1.73, p>.17]$.

For the proportion of nonwords recalled in correct position, there was no main effect of associative value $(F<1)$, so high- and low-associative nonwords did not differ on position accuracy. There was a main effect of intralist similarity $[F(3,68)=36.94, p<.001]$, which means that there was a classical PSE on position accuracy even for nonwords, consistent with previous findings. Distinct nonwords have higher position accuracy than all the 
other phonological categories [distinct vs. consonant frame nonwords, $t(71)=7.32, p<.001$; distinct vs. rhyme nonwords, $t(71)=9.41, p<.001$; distinct vs. similar nonrhyme nonwords, $t(71)=5.96, p<.001]$. These findings are consistent with the notion that the PSE occurs regardless of lexicality on position accuracy scores.

Error patterns. The four error types were intrusions (extralist items), repetitions (incorrect repetitions of an otherwise correct list item), omissions (no response given for a particular position in a list), and transpositions (confusion of order for an otherwise correct list item). Mean proportions of errors per list position were calculated. Error patterns for words and nonwords are presented in Tables 8 and 9, respectively. The protocol of error scores is exhaustive, in the sense that the sum of intrusions, repetitions, omissions, and transpositions equals 1 minus the serial recall score. With words, the error types can be ranked in the following order, according to frequency: omissions $>$ transpositions $>$ intrusions $>$ repetitions. Repetitions hardly ever occurred in this experiment, since the required written responses were efficient reminders of previous responses. ANOVAs for repeated measures were performed on the average probability per presented item for each of the error types. For words, there was a main effect of intralist similarity on transpositions, which reflects the fact that transpositions occurred more frequently for consonant frame and rhyme words than for distinct words and similar nonrhyme words $[F(3,68)=35.76, p<.001]$. In addition, omissions were more frequent for similar nonrhyme words than for consonant frame, rhyme, and distinct words $[F(3,68)=15.83$, $p<.001]$. Intrusions occurred more frequently with distinct and similar nonrhyme words than with consonant frame and rhyme words $[F(3,68)=7.56, p<.001]$.

For nonwords, the error types can be ranked in the following order, according to frequency: intrusions $>$ omissions $>$ transpositions $>$ repetitions. There was a main effect of intralist similarity on intrusions $[F(3,68)=$ $103.72, p<.001]$, which reflects the fact that consonant frame nonwords and rhyme nonwords had fewer intrusions than distinct and similar nonrhyme nonwords did. There was also a main effect of intralist similarity on omissions $[F(3,68)=64.08, p<.001]$, which reflects the fact that consonant frame nonwords and rhyme nonwords also had fewer omissions than distinct and similar nonrhyme nonwords did. In addition, transpositions occurred more frequently with consonant frame and rhyme nonwords than with distinct nonwords and similar nonrhyme nonwords $[F(3,68)=49.45, p<.001]$. Interestingly, omissions increased for similar nonrhyme and distinct nonwords in the blocked condition $[F(3,68)=3.98$, $p<.05]$.

Summary. The results of Experiment 2 are less convincing than the results of Experiment 1. Mixed versus blockwise presentation of phonological conditions did not affect the PSE as much as the manipulation of vowels in Experiment 1 did. Although it was assumed beforehand that blockwise presentation should cause more PI for distinct lists, PI was even larger for similar nonrhyme items. This finding is difficult to interpret at the present time, and clearly the effects of phonological similarity are much more complex than previously was assumed. Blockwise presentation tended to improve recall of rhyme items. This finding was expected because adjacent lists of rhyme items are assumed to have greater distinctiveness than adjacent lists of distinct items do. However, in Experiment 2, each block consisted of only four lists, and it remains to be seen whether larger blocks will create clearer differences between mixed versus blockwise presentation. Finally, there was no larger disruptive effect of blockwise presentation for nonwords than for words. The latter finding is consistent with the results in Experiment 1 and rules out the hypothesis that the reverse PSE with nonwords is due to differences in interlist interference across lexical conditions. Rather, the extremely low item recall score for phonologically distinct nonwords seems to be responsible for the reverse PSE in serial recall.

\section{GENERAL DISCUSSION}

The classical PSE in ISR has been known for 40 years, but until recently researchers have focused on a rather limited manipulation of intralist similarity. The present study is the first systematic investigation of the relationship between item similarity, list similarity, and lexicality in the research literature. It is argued that the manipulation of intralist similarity inherently affects the similarity of lists across trials, so that PSE is the confound effect of both intralist and interlist interference (see Table 1). Most important, lists of distinct items are assumed to be less distinct than lists of rhyme items. Thus, it is predicted

Table 8

Proportion of Errors According to Error Type for Words in Experiment 2

\begin{tabular}{|c|c|c|c|c|c|c|c|c|}
\hline \multirow[b]{2}{*}{ Words } & \multicolumn{2}{|c|}{ Transpositions } & \multicolumn{2}{|c|}{ Intrusions } & \multicolumn{2}{|c|}{ Repetitions } & \multicolumn{2}{|c|}{ Omissions } \\
\hline & $\mathrm{M}$ & B & M & $\mathrm{B}$ & $\mathrm{M}$ & $\mathrm{B}$ & M & B \\
\hline Distinct & .06 & .08 & .10 & .08 & .00 & .01 & .21 & .21 \\
\hline Similar nonrhyme & .06 & .08 & .09 & .08 & .01 & .00 & .27 & .33 \\
\hline Rhyme & .20 & .15 & .06 & .05 & .01 & .01 & .22 & .24 \\
\hline Consonant frame & .14 & .16 & .04 & .06 & .01 & .01 & .22 & .20 \\
\hline$M$ & .12 & .12 & .07 & .07 & .01 & .01 & .23 & .25 \\
\hline
\end{tabular}

Note-M, mixed order presentation of intralist conditions; B, blocked order presentation of intralist conditions. 
Table 9

Proportion of Errors According to Error Type for Nonwords in Experiment 2

\begin{tabular}{|c|c|c|c|c|c|c|c|c|}
\hline \multirow[b]{2}{*}{ Nonwords } & \multicolumn{2}{|c|}{ Transpositions } & \multicolumn{2}{|c|}{ Intrusions } & \multicolumn{2}{|c|}{ Repetitions } & \multicolumn{2}{|c|}{ Omissions } \\
\hline & $\mathrm{M}$ & $\mathrm{B}$ & $\mathrm{M}$ & $\mathrm{B}$ & $\mathrm{M}$ & $\mathrm{B}$ & $\mathrm{M}$ & B \\
\hline \multicolumn{9}{|l|}{ High associative } \\
\hline Distinct & .04 & .04 & .35 & .33 & .01 & .00 & .16 & .21 \\
\hline Similar nonrhyme & .05 & .07 & .30 & .34 & .00 & .00 & .21 & .26 \\
\hline Rhyme & .16 & .15 & .07 & .07 & .01 & .01 & .12 & .10 \\
\hline Consonant frame & .13 & .18 & .09 & .08 & .01 & .01 & .10 & .11 \\
\hline$M$ & .10 & .11 & .20 & .21 & .01 & .01 & .15 & .17 \\
\hline \multicolumn{9}{|l|}{ Low associative } \\
\hline Distinct & .03 & .02 & .36 & .35 & .00 & .00 & .17 & .20 \\
\hline Similar nonrhyme & .08 & .05 & .34 & .31 & .01 & .02 & .24 & .31 \\
\hline Rhyme & .18 & .16 & .10 & .07 & .01 & .01 & .17 & .16 \\
\hline Consonant frame & .11 & .16 & .13 & .10 & .01 & .01 & .10 & .10 \\
\hline$M$ & .10 & .10 & .23 & .21 & .01 & .01 & .17 & .19 \\
\hline
\end{tabular}

Note- $-\mathrm{M}$, mixed order presentation of intralist conditions; B, blocked order presentation of intralist conditions.

that PI across trials occurs more often during recall of distinct items than during recall of rhyme items.

A distinction was made between high- and lowassociative nonwords in the present study. Memory span was higher for high-associative nonwords than for lowassociative nonwords, but otherwise, associative value did not interact with intralist similarity and interlist similarity. The following discussion is thus about the relationship between lexicality, intralist similarity, and interlist similarity.

\section{Intralist Similarity}

In the present study, phonological similarity was varied in numerous ways, across both items and lists. Recall of visually presented words and nonwords was compared in two tasks involving ISR. There was a replication of the PSE for words and the reversal of the PSE for nonwords previously established with auditory presentation (Lian \& Karlsen, 2004; Lian et al., 2004; Lian et al., 2001). Distinct words were better remembered in the correct order than were words that rhymed, shared the middle vowel, or shared the consonant frame. Distinct nonwords, on the other hand, were recalled worse than were nonwords that rhymed or shared the consonant frame. Thus, there was a replication of the interaction between lexicality and intralist similarity.

The present study rules out the hypothesis that the reverse PSE for nonwords is due to a larger disruptive effect of interlist similarity (Lian et al., 2004). Instead, differences in item recall across phonological and lexical conditions appear to be the cause of the reversal. Fallon et al. (1999) distinguished between scores for item recall, serial recall, and position accuracy. This scoring procedure does not permit a complete disentanglement of item and order memory (see Neath, 1999), but it does allow for a more detailed analysis of performance in ISR. In the present study, the interaction between lexicality and intralist similarity occurred for both the serial recall score and the item recall score (items recalled correctly regardless of order). Most prominent models of VSTM account for the PSE in terms of a higher number of transpositions during recall of phonologically similar items (e.g., Baddeley, 1986; Burgess \& Hitch, 1999; Henson, 1998; Nairne, 1990a; Neath, 1999; Page \& Norris, 1998). In the present study, transpositions were indeed more frequent for similar items, regardless of lexicality, in accord with these models. This difference persists even when some of the variance in item recall is controlled for by considering position accuracy scores (the ratio between serial recall and item recall). In fact, there is no interaction between phonological similarity and lexicality on position accuracy, which is clearly in accord with the models. Thus, in order to account for the reversal of the PSE in the serial recall score, prominent VSTM models could be updated by including a parameter that predicts the item recall score by considering the lexical status and the associative value of the stimuli to be remembered.

The present study has shown that the PSE rests on the premise that item recall for phonologically similar lists does not significantly exceed item recall for phonologically distinct lists. As can be seen in Tables 2, 3, 6, and 7 , the traditional serial recall score is inflated by the item recall score, but the position accuracy score less so. Thus, intralist similarity has different effects on the serial recall score and the position accuracy score. The item recall scores in Experiments 1 and 2 show that intralist similarity is an efficient retrieval cue for nonwords, probably both because it helps generate a more limited set of recall candidates and because some information can be chunked across list items. The item recall score is much higher for words than for nonwords; in other words, there are more recall candidates available during retrieval, causing an increase in the likelihood of transpositions. Thus, the positive retrieval cuing effect due to item similarity is masked by the much larger negative effect of confusions between similar recall candidates.

The hypothesis that the reverse PSE is due to differences in item recall also explains why the PSE disappears for words with longer retention intervals (Conrad, 1967; Estes, 1973; Healy, 1975; Nairne \& Neumann, 
1993). When item recall drops as a function of retention interval, there are still fewer activated recall candidates to confuse. Thus, the positive effect of cuing is less likely to be masked by transposition errors. Furthermore, the cuing hypothesis explains why the PSE is sometimes reversed with words (Nairne \& Kelley, 1999; Tehan et al., 2001). Item recall is reduced when there are no repetitions across lists (i.e., open sets of stimuli). Longer, filled retention intervals will also reduce item recall, as compared with shorter retention intervals. A cuing advantage of similar items is thus less likely to be masked by transposition errors. That is, the item recall score is sensitive to cuing effects (Tehan et al., 2001), whereas the position accuracy score is sensitive to transposition errors (Fallon et al., 1999). The serial recall score is confounded by the two opposing effects of intralist similarity.

\section{Interlist Similarity}

So far, we have seen that intralist similarity impairs serial recall of words while improving performance with nonwords. The same pattern holds for interlist similarity in Experiment 1. Both types of similarity impair recall of words while improving performance with nonwords. In Experiment 1, distinct versus rhyme items were presented blockwise, and vowels were either switched across lists or kept constant, so interlist similarity was either low or high. The interaction between lexicality and interlist similarity on the serial recall score was not present in Experiment 2 . In that experiment, however, interlist similarity was manipulated to a lesser degree, and the disentanglement between intralist and interlist similarity was weaker. In Experiment 2, vowels were always switched across lists. This shift is likely to cause release from PI for lists of rhyme items across interlist conditions.

The assumption that interlist similarity is inherently greater for distinct items than for rhyme items in the typical experiment, regardless of the effect it has on performance, could not be tested directly in the present study. Nonetheless, the PSE, as defined by the difference between rhyme items and distinct items, was modulated by interlist similarity, irrespective of lexicality. Interlist similarity levels in Experiments 1 and 2 may be ranked in the following order: high interlist similarity in Experiment 1 (Level 1) > low interlist similarity in Experiment 1 and blocked condition in Experiment 2 (Level 2) > mixed condition in Experiment 2 (Level 3), and the PSE was inversely related to interlist similarity (see Table 10). The PSE was lowest at Level 1, higher at Level 2, and still higher at Level 3. The highest interlist similarity condition (Level 1) is novel and extreme. In typical experiments, interlist similarity is probably closer to Level 2. Thus, when trials are blocked according to their phonological and lexical status and vowels are held constant within a list but changed across lists, each new trial of phonologically similar items can be interpreted as a salient phonological category shift, causing less interlist interference (or PI) between trials. Items within the list may be interpreted as members of the same phonological category. Consequently, intralist interference (or transposi-

\begin{tabular}{|c|c|c|c|c|}
\hline \multicolumn{5}{|c|}{$\begin{array}{c}\text { Table } 10 \\
\text { Modulating the Phonological Similarity Effect (PSE) Observed } \\
\text { in Experiments } 1 \text { and } 2 \text { as a Function of Interlist Similarity } \\
\end{array}$} \\
\hline & \multicolumn{2}{|c|}{ Experiment 2} & \multicolumn{2}{|c|}{ Experiment 1} \\
\hline & Mixed & Blocked & Different Vowel & Same Vowel \\
\hline Words & .12 & .07 & .08 & .01 \\
\hline Nonwords & -.14 & -.19 & -.16 & -.25 \\
\hline
\end{tabular}

tions) should be considerable. Because lists of distinct items do not imply a salient phonological category shift, interlist interference should be particularly high for these lists.

The hypothesis above is difficult to test directly. Nevertheless, it is clear that interlist similarity modulates the PSE. The interactions between interlist and intralist similarity in Experiments 1 and 2 show that interlist similarity improves serial recall of rhyme items and reduces serial recall of distinct items. Furthermore, in Experiment 1 , interlist similarity caused fewer transpositions for rhyme items, while at the same time producing more intrusions for distinct items.

There was an interaction between lexicality of items and error pattern in both Experiments 1 and 2, consistent with previous findings (Lian et al., 2004). Transposition errors occur more often with words (particularly, phonologically similar words), and intrusions are more common with nonwords (particularly, phonologically distinct nonwords). Lian et al. (2004) suggested that this interaction, together with the interaction between lexicality and phonological intralist similarity, relates to differences in interlist interference across lexical and intralist conditions. More specifically, it was hypothesized that interlist interference is greater with nonwords than with words. Contrary to Lian et al.'s (2004) predictions, there was no three-way interaction between intralist similarity, interlist similarity, and lexicality in the present study. The effect of interlist similarity was no higher for distinct nonwords than for words. Thus, memory load, not interlist interference, is the probable cause of the many intrusions and the clear drop in recall associated with distinct nonwords, as compared with the other lexical and phonological conditions.

The fact that interlist similarity impaired recall of words while improving recall of nonwords in Experiment 1 is also contrary to the prediction by Lian et al. (2004) and suggests that PI is more common for words than for nonwords. The analogous effects of intralist and interlist interference reflect the effectiveness of similarity as a retrieval cue and its negative effect on position accuracy when similar recall candidates compete for retrieval. The two opposing effects of phonological similarity affect recall for words and nonwords differently. For words, the negative effect dominates, whereas for nonwords the positive effect masks the negative effect. 
The differential effects of intralist and interlist similarity on the recall of words and nonwords echo another effect in the short-term memory literature-namely, that of repetition blindness. Accuracy of report of words in a rapidly presented sequence is reduced when one word is a repetition of a previous word. This effect is also known as the Ranschburg effect. However, with pronounceable nonwords, or pseudohomophones, repetition improves recall (Campbell, Fugelsang, \& Hernberg, 2002; V. Coltheart \& Langdon, 2003). That is, within-list repetition, item similarity, and list similarity have opposite effects on the ISR for words and nonwords.

\section{Conclusions}

The present study has shown that PI or interlist interference interacts with both lexicality and phonological similarity, but the lack of a three-way interaction rules out an explanation of the reverse PSE for nonwords in terms of differences in interlist interference. Shared phonemes across items within a list do not provide better release from PI for nonwords than for words, but they do provide efficient retrieval cues, probably both because shared phonemes help generate a more limited set of recall candidates and because the shared information can be chunked across list items. Although position accuracy is little affected by lexicality, there is clearly a drop in item recall of nonwords. This is particularly the case with low-associative nonwords, which are assumed to have been the least connected to long-term memory of the stimuli materials in the present study. The advantage of distinct words gets smaller the greater the interlist similarity (see Table 10). This finding indicates that the classical PSE is the combined result of intralist and interlist interference, in the sense that interlist interference modulates the size of the PSE. In order to account for the reversal of the PSE in the serial recall score, VSTM models (e.g., Baddeley, 1986; Burgess \& Hitch, 1999; Nairne, 1990a) could be updated by including an item recall parameter that takes into consideration the lexical status and associative value of the stimuli to be remembered.

\section{REFERENCES}

BAdDeley, A. D. (1966). Short-term memory for word sequences as a function of acoustic, semantic and formal similarity. Quarterly Journal of Experimental Psychology, 18, 362-365.

Baddeley, A. D. (1986). Working memory. Oxford: Oxford University Press, Clarendon Press.

BAdDEley, A. D. (2003). Working memory: Looking back and looking forward. Nature Reviews Neuroscience, 4, 829-839.

Baddeley, A. D., Gathercole, S., \& Papagno, C. (1998). The phonological loop as a language learning device. Psychological Review, 105, 158-173.

Baddeley, A. D., \& Hitch, G. J. (1974). Working memory. In G. H. Bower (Ed.), The psychology of learning and motivation (Vol. 8, pp. 47-89). London: Academic Press.

BLOCK, R. A. (1971). Effects of instructions to forget in short-term memory. Journal of Experimental Psychology, 89, 1-9.

Brown, G. D. A., \& Hulme, C. (1995). Modelling item length effects in memory span: No rehearsal needed? Journal of Memory \& Language, 34, 594-621.

Brown, G. D. A., Preece, T., \& Hulme, C. (2000). Oscillator-based memory for serial order. Psychological Review, 107, 127-181.
Bruce, D., \& Murdock, B. B., Jr. (1968). Acoustic similarity effects on memory for paired associates. Journal of Verbal Learning \& Verbal Behavior, 7, 627-631.

Burgess, N., \& Hitch, G. J. (1992). Toward a network model of the articulatory loop. Journal of Memory \& Language, 31, 429-460.

Burgess, N., \& Hitch, G. J. (1999). Memory for serial order: A network model of the phonological loop and its timing. Psychological Review, 106, 551-581.

Campbell, J. I. D., Fugelsang, J. A., \& Hernberg, V. D. (2002). Effects of lexicality and distinctiveness on repetition blindness. Journal of Experimental Psychology: Human Perception \& Performance, 28, 948-962.

Coltheart, M., \& Geffen, G. (1970). Grammar and memory: I. Phonological similarity and proactive interference. Cognitive Psychology, 1, 215-224.

Coltheart, V., \& Langdon, R. (2003). Repetition blindness for words yet repetition advantage for nonwords. Journal of Experimental Psychology: Learning, Memory, \& Cognition, 29, 171-185.

CONRAD, R. (1965). Order errors in immediate recall of sequences. Journal of Verbal Learning \& Verbal Behavior, 4, 161-169.

CONRAD, R. (1967). Interference or decay over short retention intervals? Journal of Verbal Learning \& Verbal Behavior, 6, 49-54.

Conrad, R., Baddeley, A. D., \& Hull, A. J. (1966). Rate of presentation and the acoustic similarity effect in short-term memory. Psychonomic Science, 5, 233-234.

Conrad, R., Freeman, P. R., \& Hull, A. J. (1965). Acoustic factors versus language factors in short-term memory. Psychonomic Science, 3, 57-58.

ConRad, R., \& Hull, A. J. (1964). Information, acoustic confusion and memory span. British Journal of Psychology, 55, 429-432.

Cowan, N. (2001). The magical number 4 in short-term memory: A reconsideration of mental storage capacity. Behavioral \& Brain Sciences, 24, 87-185.

CrowDER, R. G. (1976). The locus of the lexicality effect in short-term memory for phonologically identical lists. Bulletin of the Psychonomic Society, 7, 361-363.

Dempster, F. N., \& CoONEY, J. B. (1982). Individual differences in digit span, susceptibility to proactive interference, and aptitude/achievement test scores. Intelligence, 6, 399-416.

DrEWNOWSKI, A. (1980). Attributes and priorities in short-term recall: A new model of memory span. Journal of Experimental Psychology: General, 109, 208-250.

ELLIS, A. W. (1980). Errors in speech and short-term memory: The effects of phonemic similarity and syllable position. Journal of Verbal Learning \& Verbal Behavior, 19, 624-634.

Estes, W. K. (1973). Phonemic coding and rehearsal in short-term memory for letter strings. Journal of Verbal Learning \& Verbal Behavior, 12, 360-372.

Fallon, A. B., Groves, K., \& Tehan, G. (1999). Phonological similarity and trace degradation in the serial recall task: When CAT helps RAT, but not MAN. International Journal of Psychology, 34, 301-307.

Gathercole, S. E. (1997). Models of verbal short-term memory. In M. A. Conway (Ed.), Cognitive models of memory (pp. 13-44). Cambridge, MA: MIT Press.

Gathercole, S. E., Frankish, C. R., Pickering, S. J., \& Peaker, S. (1999). Phonotactic influences on short-term memory. Journal of Experimental Psychology: Learning, Memory, \& Cognition, 25, 8495.

Gathercole, S. E., \& Martin, A. (1996). Interactive processes in phonological memory. In S. E. Gathercole (Ed.), Models of shortterm memory (pp. 73-100). Hove, U.K.: Psychology Press.

Gathercole, S. E., Pickering, S. J., Hall, M., \& Peaker, S. M. (2001). Dissociable lexical and phonological influences on serial recognition and serial recall. Quarterly Journal of Experimental Psychology, 54A, 1-30.

Gillund, G., \& Shiffrin, R. M. (1984). A retrieval model for both recognition and recall. Psychological Review, 91, 1-67.

Glassman, W. E. (1972). Subvocal activity and acoustic confusions in short-term memory. Journal of Experimental Psychology, 96, 164-169.

Glasspool, D. W. (1995). Competitive queuing and the articulatory loop. In J. P. Levy, D. Bairaktaris, \& P. Cairns (Eds.), Connectionist models of memory and language (pp. 5-30). London: UCL Press. 
Graf, R., Braun, M., Jacobs, A. M., \& HellbrücK, J. (2002). Language processing and short-term memory: The gradual phonological similarity effect and irrelevant speech. Psychologische Beiträge, 44, 203-222.

Halford, G. S., Maybery, M. T., \& Bain, J. D. (1988). Set-size effects in primary memory: An age-related capacity limitation? Memory \& Cognition, 16, 480-487.

HEALY, A. F. (1974). Separating item from order information in short-term memory. Journal of Verbal Learning \& Verbal Behavior, 13, 644-655.

Healy, A. F. (1975). Coding of temporal-spatial patterns in short-term memory. Journal of Verbal Learning \& Verbal Behavior, 14, 481-495.

Henriksen, K., Fleming, J. P., \& Pilichowski, D. L. (1974). Acoustic similarity and release from proactive inhibition. Psychological Reports, 34, 335-338.

Henson, R. N. A. (1998). Short-term memory for serial order: The start-end model. Cognitive Psychology, 36, 73-137.

Henson, R. [N. A.], Hartley, T., Burgess, N., Hitch, G., \& Flude, B. (2003). Selective interference with verbal short-term memory for serial order information: A new paradigm and tests of a timing-signal hypothesis. Quarterly Journal of Experimental Psychology, 56A, 1307-1334.

Henson, R. N. A., Norris, D. G., Page, M. P. A., \& Baddeley, A. D. (1996). Unchained memory: Error patterns rule out chaining models of immediate serial recall. Quarterly Journal of Experimental Psychology, 49A, 80-115.

Houghton, G. (1990). The problem of serial order: A neural network model of sequence learning and recall. In R. Dale, C. Mellish, \& M. Zock (Eds.), Current research in natural language generation (pp. 287-319). London: Academic Press.

Hulme, C., Newton, P., Cowan, N., Stuart, G., \& Brown, G. (1999). Think before you speak: Pauses, memory search, and trace redintegration processes in verbal memory span. Journal of Experimental Psychology: Learning, Memory, \& Cognition, 25, 447-463.

KarLSEn, P. J., \& SNODGRass, J. G. (2004). The word-frequency paradox for recognition/recall occurs for pictures. Psychological Research, 68, 271-276.

Keppel, G., \& Underwood, B. J. (1962). Proactive inhibition in shortterm retention of single items. Journal of Verbal Learning \& Verbal Behavior, 1, 153-161.

LEWANDOWSKY, S., \& FARRELL, S. (2000). A redintegration account of the effects of speech rate, lexicality, and word frequency in immediate serial recall. Psychological Research, 63, 163-173.

Lian, A., \& KARLSEN, P. J. (2004). Advantages and disadvantages of phonological similarity in serial recall and serial recognition of nonwords. Memory \& Cognition, 32, 223-234.

Lian, A., Karlsen, P. J., \& Eriksen, T. (2004). Opposing effects of phonological similarity on item and order memory of words and nonwords in the serial recall task. Memory, 12, 314-337.

Lian, A., Karlsen, P. J., \& Winsvold, B. (2001). A re-evaluation of the phonological similarity effect in adults' short-term memory of words and nonwords. Memory, 9, 281-299.

LoEss, H. (1968). Short-term memory and item similarity. Journal of Verbal Learning \& Verbal Behavior, 8, 240-247.

Longoni, A. M., Richardson, J. T. E., \& Aiello, A. (1993). Articulatory rehearsal and phonological storage in working memory. Memory \& Cognition, 21, 11-22.

Lustig, C., \& HASHER, L. (2002). Working memory span: The effect of prior learning. American Journal of Psychology, 115, 89-101.

Lustig, C., May, C. P., \& Hasher, L. (2001). Working memory span and the role of proactive interference. Journal of Experimental Psychology: General, 130, 199-207.
Miller, G. A. (1956). The magical number seven, plus or minus two: Some limits on our capacity for processing information. Psychological Review, 63, 81-97.

Mueller, S. T., Seymour, T. L., Kieras, D. E., \& Meyer, D. E. (2003). Theoretical implications of articulatory duration, phonological similarity, and phonological complexity in verbal working memory. Journal of Experimental Psychology: Learning, Memory, \& Cognition, 29, 1353-1380.

Multhaup, K. S., Balota, D. A., \& Cowan, N. (1996). Implications of aging, lexicality, and item length for the mechanisms underlying memory span. Psychonomic Bulletin \& Review, 3, 112-120.

MURDOCK, B. B., JR., \& VOM SAAL, W. (1967). Transpositions in shortterm memory. Journal of Experimental Psychology, 74, 137-143.

NAIRNE, J. S. (1990a). A feature model of immediate memory. Memory \& Cognition, 18, 251-269.

NAIRNE, J. S. (1990b). Similarity and long-term memory for order. Journal of Memory \& Language, 29, 733-746.

Nairne, J. S., \& Kelley, M. R. (1999). Reversing the phonological similarity effect. Memory \& Cognition, 27, 45-53.

NAirne, J. S., \& Kelley, M. R. (2004). Separating item and order information through process dissociation. Journal of Memory \& Language, 50, 113-133.

NaIRne, J. S., \& Neumann, C. (1993). Enhancing effects of similarity on long-term memory for order. Journal of Experimental Psychology: Learning, Memory, \& Cognition, 19, 329-337.

NeATH, I. (1999). Modelling the disruptive effects of irrelevant speech on order information. International Journal of Psychology, 34, 410-418.

Neath, I., \& NaIRne, J. S. (1995). Word-length effects in immediate memory: Overwriting trace decay theory. Psychonomic Bulletin \& Review, 2, 429-441.

Oslo Corpus of Tagged Norwegian Texts (2000). Available at http:// tekstlab.uio.no/norsk/bokmaal/english.html.

PAGE, M. P. A., \& NorRIS, D. (1998). The primacy model: A new model of immediate serial recall. Psychological Review, 105, 761-781.

Sanders, A. F., \& Willemsen, E. M. (1978). Proactive interference in immediate serial recall. Acta Psychologica, 42, 29-38.

SCHWEICKeRT, R. (1993). A multinomial processing tree model for degradation and redintegration in immediate recall. Memory \& $\mathrm{Cog}_{-}$ nition, 21, 168-175.

Schweickert, R., Guentert, L., \& Hersberger, L. (1990). Phonological similarity, pronunciation rate, and memory span. Psychological Science, 1, 74-77.

Tehan, G., Hendry, L., \& KocinsKi, D. (2001). Word length and phonological similarity in simple, complex, and delayed serial recall tasks: Implications for working memory. Memory, 9, 333-348.

Tehan, G., \& Humphreys, M. S. (1995). Transient phonemic codes and immunity to proactive interference. Memory \& Cognition, 23, 181191.

Tehan, G., \& Humphreys, M. S. (1998). Creating proactive interference in immediate recall: Building a DOG from a DART, a MOP, and a FIG. Memory \& Cognition, 26, 477-489.

WiCKELGREN, W. C. (1965). Short-term memory for phonemically similar lists. American Journal of Psychology, 78, 567-574.

WickENS, D. D. (1970). Encoding categories of words: An empirical approach to meaning. Psychological Review, 77, 1-15.

Wickens, D. D., Born, D. G., \& Allen, C. K. (1963). Proactive inhibition and item similarity in short-term memory. Journal of Verbal Learning \& Verbal Behavior, 2, 440-445.

WRIGHT, J. H. (1967). Effects of formal interitem similarity and length of retention interval on proactive inhibition of short-term memory. Journal of Experimental Psychology, 75, 386-395. 


\section{APPENDIX A \\ Study Lists of Words, High-Associative Nonwords, and Low-Associative Nonwords Presented in Experiment 1}

There were four lists of each lexical status in each phonological condition. SS, similar at item level (rhyme) and list level; SD, similar at item level (rhyme), distinct at list level; DS, distinct at item level, similar at list level; DD, distinct at both item level and list level. Trigrams that were repeated once across lists are in italic; trigrams that were crossovers from the other category of associative value are underlined. There was one error in SD for high-associative nonwords, List 3, Position 3: lef (marked *) should have been lep.

Words. SS: lang, tang, sang, trang, klang, fang; mann, rand, kan, sann, hand, land; tall, ball, hall, fall, kall, rall; hakk, takk, sjakk, makk, lakk, brakk. SD: rull, tull, kull, full, null, gull; nøtt, født, rødt, kjøtt, bløtt, dødt; sild, dill, mild, snill, grill, spill; grell, sprell, smell, selv, hell, trell. DS: bønn, gutt, krill, fjell, ratt, hekk; grønn, krutt, drill, stell, bratt, flekk; drønn, mutt, til, skjell, kratt, smekk; sønn, brutt, pill, meld, dratt, kjekk. DD: hund, mark, skutt, vekk, jobb, hvitt; bank, pluss, stikk, felt, bryst, fusk; luft, takt, frisk, hull, press, kyst; hems, tung, gjeld, hals, tekst, flukt.

High-associative nonwords. SS: kub, gub, sub, tub, lub; guf, luf, duf, tuf, suf; dup, tup, lup, kup, sup; ruv, suv, kuv, guv, $d u v$. SD: dob, tob, kob, rob, lob; gaf, saf, kaf, taf, laf; rep, dep, lef*, tep, sep; kiv, div, riv, tiv, liv. DS: gof, tip, sav, dåp, leb; sof, gip, tav, kåp, deb; lof, dip, gav, tåp, keb; kof, sip, kav, såp, teb. DD: lap, rib, dov, sef, køb; rov, løf, kop, tab, tev; dif, lab, tev, lop, tåf; såb, gif, rop, lev, kap.

Low-associative nonwords. SS: råb, tåb, dåb, låb, gåb; låf, dåf, gåf, såf, råf; tåp, råp, låp, dåp, gåp; dåv, tåv, kåv, råv, såv. SD: gib, kib, dib, lib, sib; gøf, søf, røf, køf, døf; dap, kap, tap, gap, sap; kev, rev, tev, sev, dev. DS: tøb, kif, $\underline{d u v}$, lop , gef; døb, tif, ruv, gop, lef; røb, rif, luv, top, kef; gøb, sif, tuv, dop, tef. DD: dub, kuf, røv, gep, dav; laf, reb, gøp, siv, tof; rup, døv, geb, giv, rof; seb, tov, dip, raf, køv.

\section{APPENDIX B \\ Study Lists of Words, High-Associative Nonwords, and Low-Associative Nonwords Presented in Experiment 2}

There were four lists of each lexical status in each phonological condition. Trigrams that were repeated once across lists are in italic; trigrams that were crossovers from the other category of associative value are underlined. There was one error in similar nonrhyme for high-associative nonwords, List 1, Position 2: heb (marked *) should have had a different initial consonant.

Words. Consonant frame lists: trekk, tråkk, trakk, trøkk, trikk, trykk; ditt, dødt, dytt, datt, dott, dett; full, fell, fyll, fold, fall, føll; sånn, sinn, send, sann, sønn, synd. Rhyme lists: brønn, lønn, kjønn, drønn, bønn, grønn; kvekk, flekk, kjekk, brekk, smekk, sjekk; lett, rett, nett, tett, hett; ball, tall, hall, knall, skal, trall. Similar nonrhyme lists: brann, krakk, pall, smatt, tann, matt; sunn, tull, sukk, munn, gutt, hull; trinn, skikk, grill, skritt, klikk, snill; penn, dekk, hell, brett, hekk, mett. Distinct lists: takk, spenn, lokk, sølv, bunn, sprett; hatt, smukk, spill, flokk, krøll, venn; skatt, drill, vann, frekk, trøtt, slukk; bukk, han, grell, vinn, dukk, rødt.

High-associative nonwords. Consonant frame lists: kåb, keb, kub, kob, køb; lof, lef, løf, lif, luf; sip, søp, sop, sup, såp; tov, tev, tav, tøv, tiv. Rhyme lists: lab, rab, tab, sab, kab; gof, dof, lof, kof, sof; lep, dep, rep, tep, sep; riv, div, liv, tiv, kiv. Similar nonrhyme lists: gaf, kap, sav, taf, lap; heb*, ref, gev, leb, sef; lob, dov, gof, tob, kop; duf, suv, dup, tub, guv. Distinct lists: deb, løv, kåp, dif, sob; gip, lub, røp, gav, kåf; def, låv, sof, rib, lup; søv, rob, kaf, gip, rap.

Low-associative nonwords. Consonant frame lists: duv, dev, døv, dåv, dav; gop, gep, gåp, gøp, gup; taf, tuf, tef, tof, tif; råb, rub, reb, $\underline{r a b}$, røb. Rhyme lists: sib, gib, dib, lib, kib; gøf, røf, køb, døf, søf; kap, sap, tap, gap, dap; gåv, råv, tåv, kåv, såv. Similar nonrhyme lists: kef, geb, sev, kep, lef; døb, køb, gøv, tøp, røv; råp, dåf, låb, gåf, låp; kov, top, dof, gob, rof. Distinct lists: køv, dop, seb, daf, rup; dip, tuv, dåp, sib, låf; gab, kif, tov, døp, gef; laf, dab, giv, lov, kuf.

(Manuscript received November 5, 2003;

revision accepted for publication July 22, 2004.) 